\title{
The Effect of Social Media on Researchers' Academic Performance through Collaborative Learning in Malaysian Higher Education
}

\author{
Waleed Mugahed Al-rahmi* \\ Mohd Shahizan Othman \\ Lizawati Mi Yusuf \\ Department of Information System, Faculty of computing, Universiti Teknologi Malaysia, Johor Bahru, 81310, Malaysia \\ *Email: abumunir82@yahoo.com
}

Doi:10.5901/mjss.2015.v6n4s1p193

\begin{abstract}
This study aims to explain the way social media contributes to the enhancement of collaborative learning among researchers Malaysian higher education. The sample comprised of 723 researchers. The findings showed that introvert researchers perceive social media to help in increasing collaborative learning and improving their performance. These researchers are more inclined to communicate through social media as opposed to face-to-face. In addition, the sample researchers are inclined to utilize social media. Therefore, Malaysian higher education institutions are recommended to employ social media in enhancing the researchers' collaborative learning. The researcher employs the use of theory of technology acceptance model (TAM) for this purpose. The results show that collaborative learning positively and significantly relates to impact intention to use social media for collaborative learning to improve performance of researchers in Malaysian higher education.
\end{abstract}

Keywords: social media, TAM model, collaborative learning, satisfaction, performance of the researchers and Higher education.

\section{Introduction}

In the current times, we can see a lot of technology tools that have been made available to facilitate sharing, which include electronic bulletin boards, databases, forums, e-mails, blogs, as well as social networking sites. This study attempts to investigate the factors that could encourage knowledge sharing through social networks. Social media network has been chosen as the medium to be studied because it is widely used all over the world today. Therefore, this study is conducted with the aim to discover what factors might lead to knowledge sharing through social networks and how social networks are used to facilitate the process. According to a research that was conducted by IDC Research (a body which actively conducts researches in Malaysia), the Internet users in Malaysia has reached 20.4 million and is predicted to increase (Syahrir and Fatin, 2009). Due to the active usage of Internet, this phenomenon has resulted in the existence of social network sites. Social network communities and websites have noted an increasing trend of use recently by business, academic communities, as well as individuals within a society. Friendster reported over 17 million users and MySpace over 20 million users in July 2005 (Ismail, 2010). The social network services and websites are expanding and producing community knowledge every second (Akiyoshi, 2008).

\section{Defining Social Media}

There is no universally agreed definition of social media, nor uniform terminology, consistent with rapid technological developments and evolving conventions and uses (Burnett and Merchant, 2011). Often researchers use terms such as Web 2.0 (Greenhow et al., 2009), social networking (Livingstone and Brake, 2010), social software (Owen et al., 2006; Minocha, 2009) or simply the internet. Web 2.0 is the most frequently used term in relation to social media. However, its meaning has changed over time, and is often used by teachers and academics in collaborative learning or interactivity. These interactive applications encompass, amongst others, social networking services (e.g. Facebook), blogs (e.g. Blogspot), microblogs (e.g. Twitter), Wikis (e.g. Wiktionary.org), forums (e.g. minecraftforum.net), video sharing (e.g. YouTube), and image sharing (e.g. Flickr) enabling people to connect for purposes of 'collaboration, contribution and community' (Anderson, 2007, p. 14). 


\subsection{Facebook, YouTube, and Twitter}

Majority of students have set up Facebook accounts with their personal profiles. They have various information such as photos and information concerning their networking group in their accounts. Their personal profile may be utilized to break the ice so that students and instructors are able to get to know each other better than a simple self-introduction in class. In other words, it can function as a community learning starter. Moreover, students can develop an in-depth bonding relationship with those having common interests, hobbies, lifestyles with them. The primary advantage of using Facebook as a community learning tool rather than using communications tools in CMS is the ongoing relationship even after school is over.

The features of Facebook include user's profile, status, friends, news feed, wall, boards for discussion, photo tagging and applications. On the basis of the above features, Facebook could work towards building a maintainable learning social network and developing an extended community learning environment.

YouTube, on the other hand, has set up a specific channel for education known as the TeacherTube for teachers to upload instructional contents to share with their fellow professionals. It offers invaluable resources for teachers as well as students. More importantly, YouTube launched another education related site about a year ago called YouTube EDU. The site aggregated thousands of free lecturers from nearly 400 universities from across the U.S. and this was impacted by MIT open source initiative in the better part of the 90s. This site enables educators and learners to access learning content for free. The dissemination of knowledge is monumental and it is a superior method to gather and emphasize all the invaluable educational content being uploaded to YouTube by institutions of higher learning (Arrington, 2009). The top social media sites prevalent in the news are Facebook, Twitter, YouTube and MySpace, and the list goes on and on. Whether or not a higher education professional has a Facebook account, there is a great change that they know about it. Both individuals and organizations make use of Facebook for information sharing - information that is work related and personal (Ewbank et al., 2010). Information may be disseminated by individuals, groups, organizations, businesses and others in the form of text, link, photo or video and share with their friends and colleagues, via personal accounts. Facebook also offers a resource for individuals to conduct instantaneous messaging and internal email through the site.

\subsection{Effective use of social media}

The review clearly demonstrated instances where social media had a valuable role in facilitating the collaborative learning and engagement of education, students and others in the learning process. For instance, connections with teachers can be made between different physical locations and outside specified class times (Chandra and Watters, 2012; DeGennaro, 2008), with groups outside the class such as other students at different levels of education (Gomez et al., 2010; Maher 2009,2010 ). The social media can be employed to enhance researchers collaborative learning on group tasks (Liu et al., 2011; Pifarre and Fisher, 2011), as well as to draw on the knowledge and skills of others to enhance their own (Zhang et al., 2007). Researchers can use the media to provide feedback and support to peers, and also share work with an audience beyond their teacher (Hastie et al., 2010). These same affordances enable teachers to monitor students' progress more closely as well as to provide timely guidance and feedback (Zywica et al., 2011). (Chandra and Watters, 2012) noted that the interactions through chat facility between teachers and students in their homes enabled the participation of those who might not normally do so in the classroom, although collaboration between students was more limited.

In the current times, several researchers attempted to utilize the trend of Web 2.0 to develop a new learning model; for instance, by the application of Blogs in learning and knowledge sharing. Subsequently, (Huang et al., 2009) proposed reinforcing collaborating learning by blogs. On the other hand, (Yang and Chen, 2008) addressed knowledge sharing by proposing a learning model of collaborative learning via knowledge sharing based on social media. Collaborative learning model requires technical support and interaction with researchers. Thus, in the present time, interaction is the top most significant issue of researchers. (Yang and Chen, 2008) also proposed the establishment of knowledge sharing communities through social media network.

\section{Conceptual Framework and Hypotheses}

This study attempts to explain the framework see figure one proposed for the impact of social media use on collaborative learning among researchers at five research universities in Malaysian higher education, with the Technology Acceptance Model (TAM) theory. The present study revealed that social media integration is linked to the collaborative learning among students. The social media variables include perceived ease of use (PEU), perceived usefulness (PU), intention to 
use social media (INUS), collaborative learning (CL) researchers satisfaction (RS) and performance of the researchers (PR).

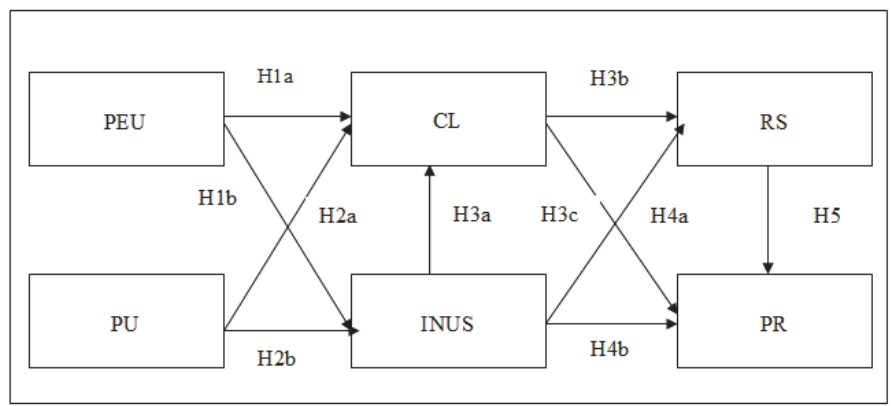

Figure 1: Conceptual framework

\subsection{Perceived Usefulness and Perceived Ease of Use}

The adopted TAM model in the present study was adapted from the Theory of Reasoned Action (TRA), in the IS field. TAM posits that perceived usefulness and perceived ease of use predicts student's use intention towards the system, with the latter mediating actual system use. In addition, perceived usefulness is also impacted by perceived ease of use. TAM has been simplified by researchers by deleting the attitude construct in the original TRA model to suit specifications (Venkatesh et al., 2003).

TAM posits that an individual's behavioral intention regarding the application use is predicted via perceived usefulness and perceived ease of use. Moreover, since its proposal by (Davis et al., 1989), it has been extensively utilized to predict use of information technology (Selim, 2003). In fact, (Davis et al., 1989) stated that perceived usefulness and perceived ease of use of social media network determine the factors towards intention to use social media network. The model identifies causal associations between social media network design variables, perceived usefulness of the social media network, perceived ease of use of the social media network, and the attitudes of individuals to the social media network use in the context of higher education. Hence, the following hypotheses are proposed;

H1a: There's a significant relationship between perceived ease of use and collaborative learning.

$\mathrm{H} 1 \mathrm{~b}$ : There's a significant relationship between perceived ease of use and intention to use social media.

H2a: There's a significant relationship between perceived usefulness and collaborative learning.

$\mathrm{H} 2 \mathrm{~b}$ : There's a significant relationship between perceived usefulness and intention to use social media.

\subsection{Intention to Use Social Media}

The intention of students to using social media network for collaborative learning is a key factor contributing to the formation of structure technology utilization models (Venkatesh et al., 2003; Davis et al., 1989). The entire theories/models are extensions of the primary principles of TRA, which posit that intention to use the system is the attitude function to individual behavior and subjective norms, which was subsequently extended to cover perceived ease of use and thus, TPB (Venkatesh and Bala, 2008). Perceived enjoyment is also deemed as a crucial users' post-adoption perception that culminates to maximized degrees of satisfaction and continuous intention (Pelling and White, 2009). In this regard, (Moon and Kim,2001) revealed that individuals who are comfortable using a web system will perceive their system interaction in a more positive light and develop a high behavior intention to use it.

H4a: There's a significant relationship between intention to use social media and researchers satisfaction.

$\mathrm{H} 4 \mathrm{~b}$ : There's a significant relationship between intention to use social media and performance of the researchers.

\subsection{Social media and Collaborative Learning}

Several current researchers have accepted that knowledge does exist in individual minds and among individuals' discourse and interactions. Such interactions result in active participation and according to (Hrastinski, 2009); active 
participation is a significant learning element. Learners have to be skilful in sharing knowledge with others and collaborating with them in face-to-face situations with the help of technology such as social media. (Kabilan et al., 2010) contended that students hold the power to creating learning communities via collaborative learning and construction of knowledge. In addition to this, (Yu et al.,2010) stated that social media tools help in realizing the development of learning communities via collaboration and communication and these lead to positive learning results.

H3a: There's a significant relationship between collaborative learning and intention to use social media.

$\mathrm{H} 3 \mathrm{~b}$ : There's a significant relationship between collaborative learning and researchers satisfaction.

$\mathrm{H} 3 \mathrm{c}$ : There's a significant relationship between collaborative learning and performance of the researchers.

\subsection{Researchers Satisfaction}

Student's satisfaction with collaborative learning through perceived ease of use and perceived usefulness (intention to use social media) is definitely a result of the collaboration process and could be referred to mean the degree that students feel an optimistic connection to his very own collaborative learning encounters (Sánchez et al, 2014; Mazman and Usluel,2010). the researchers satisfaction might have consequences on how students interact, for example whether everybody does his/her area of the work, whether group of researchers can function with one another, that help collaborative learning among researchers by using social media (Boulos et al,2006). Apparently there seem to be an enhanced trend among users to embrace the social media particularly at college level. It appears to possess transformed communication designs even at local level. The using of social media among college students appears to be growing on a daily basis and a lot of them depend on their usage for interactions and communication. According to (Smith and Caruso, 2010; Al-rahmi and Othman, 2013a; Al-rahmi et al., 2015a).

H5: There's a significant relationship between researchers satisfaction and performance of the researchers.

\subsection{Social Media and Student Learning Achievements}

Using social media in academia leads to the maximization of the student's learning experience. Students who take part in coursework involving social media experiences increased CGPA compared to those who do not (Junco, 2012b; Junco et al., 2011). Social media use results in greater CGPA and peer feedback about assignments, and course content reflections as students are enabled to openly communicate among each other and strengthen peer relationship (Arnold and Paulus, 2010b; Ebner et al., 2010). The same contention was stated by (Chen and Bryer, 2012; Heafner and Friedman, 2008). They claimed that social media use boosts students' information retention and understanding of the curricula. Findings revealed that students using social media are superior at linking course content with practical peer interactions and ultimately this supports their learning in class.

\section{Research Method}

The data collection technique for this study is dependent on questionnaires administered on researcher at Malaysian higher education. Therefore, the data collection of this research will be carried out by quantitative methodology, which are reliable and accepted and can give more reliable information obtained from the researchers within Malaysian higher education that helping to achieve the study objectives. Researchers were instructed in the questionnaires to offer information about their experiences and impact of using social media on academic performance through collaborative learning.

This study aims to answer the question, "What is the relationship between performance of researchers and intention to use social media through collaborative learning?" The following sections provide description on the methods used to answer the above question. The data for the analysis is gathered through a survey questionnaire distributed to 1141 postgraduate in the 2013/2014 academic session, the survey to offer information about their experiences and impact of using social media on collaborative learning through Technology Acceptance Model theory. The respondents were required to offer information of their experiences with using the social media tools. From the distributed questionnaires in three months duration, 723 valid responses are obtained from the Malaysian higher education. IBM SPSS (Version-20) and Amos (Version-16) were used to analyze the data.

\subsection{Sample}

Sampling is described as a statistical procedure involving the selection of subset of individual observations from a 
population, intending to generate an effective knowledge concerning the students at Malaysian higher education. Two types of sampling techniques are cited in literature namely random sampling and non-random sampling. The first type is selected for the present reason as it offers the target population equal chances to be selected. The sampling method comprises of randomly selected postgraduate students, and based on the universities website "the number of researchers who belong to the five research universities in Malaysia are as follows: UM, UKM, USM, UTM and UPM" and According to Morgan's (1970) sampling table, the sample number the researcher gauged the numbers of respondents to be seven hundred and twenty-three (723).

\subsection{Data Collection and Measurement}

This study is part of a larger study that examines the researchers' opinions about intention to use social media for collaborative learning to improve performance of researchers through technology acceptance model theory .A questionnaires of this research consist of open ended questionnaires and closed ended questionnaires survey. The questionnaires consist of 45 questions namely background information, the reason of intention to use social media, researchers perception on social media and the influence on academic performance. Aim to measurement the researchers' perceptions of social media tools influence on their academic performance.

To measure the constructs included in our framework. Was measured perceived ease of use, and perceived usefulness was measured using a subset of four items from, (Ajjan and Hartshorne,2008; Kwon and Wen,2010), intention to use social media was measured using five items from (Kim et al.,2008), and finally, Collaborative learning was measured using four items adapted from, (So and Brush,2008), researchers satisfaction was measured using five items from, (Gallini and Moely,2003) and finally, students' academic performance was measured using six items from (Banks,2006).

It was made clear that participation in the survey was voluntary and anonymous. And he final questionnaire was distributed on 1141 researchers, 723 completed the survey at the semester (February 2014). We found that of the researchers' awareness, through their perceived ease of use and perceived usefulness and their intention to use social media, encourage their intention to use, and this ultimately leads to the enhancement of active collaborative learning. This holds true for perceived ease of use, perceived usefulness and intention to use social media (Kim et al, 2007). It can therefore be stated that ease of use, usefulness That enhances intention to use social media and collaborative learning among researchers in universities to improve performance of researchers. collaborative learning (SSCL) for improving understanding construction (Yampinij et al., 2012) and the Improvement of students' academic performance by using social media through collaborative learning in higher education (Al-rahmi and Othman,2014; Al-rahmi et al., 2015b).

\section{Result and Discussion}

Background of respondents is obtained based on the result of questionnaire. the analysis result can be seen on table one below, the distribution of respondents on the basic demographic of the sample Firstly, the number of questioner respondents based on gender of researchers; the number of respondents based on their gender, which are 324 male respondents corresponding to (44.8\%) and 399 female respondents (55\%). From the number of respondents, it can be known that the number of female respondents is highest than male respondents. This is not deliberate while the distribution of questionnaire. Secondly, number of questioner respondents based on age of researchers, which are 118 respondents (16.3\%) come from 21-24 years old group, 313 respondents (43.3\%) come from 25-30 years old group, 183 respondents (25.3\%) for 30-35 years old group and 109 respondents (15.1\%) above 35 years old group. Finally, the Number of questioner respondents based on degree of researchers, which are 134 respondents $(18.5 \%)$ come from master full research, 117 respondents (16.2\%) come from master mixed mode, 136 respondents (18.8\%) for master taught course, 331 respondents (45.8\%) come from $\mathrm{PhD}$ and 5 respondents (0.7\%) come from Post-Doctoral. the number of respondents based on their field of research, which are 116 respondents (16\%) that come from field pure and applied sciences, 174 respondents (24.1\%) the field technology and engineering, 85 respondents (11.8\%) for field technology and communication, 69 respondents $(9.5 \%)$ come from social sciences, 160 respondents $(22.1 \%)$ come from educational, 100 respondents (13.8\%) come from human resource and development,14 respondents (1.9\%) come from clinical and health sciences and 5 respondents $(0.7 \%)$ come from other like faculty of engineering. 
Table 1: Number of questioner respondents based on gender, age and degree of researchers

\begin{tabular}{|c|c|c|c|c|c|}
\hline Demographic factors & Categories & Frequency & Percent & Valid Percent & Cumulative Percent \\
\hline \multirow[t]{3}{*}{ Gender } & Male & 324 & 44.8 & 44.8 & \multirow{3}{*}{$\begin{array}{c}44.8 \\
100.0\end{array}$} \\
\hline & Female & 399 & 55.2 & 55.2 & \\
\hline & Total & 723 & 100.0 & 100.0 & \\
\hline \multirow[t]{5}{*}{ Age } & $21-24$ & 118 & 16.3 & 16.3 & \multirow{5}{*}{$\begin{array}{c}16.3 \\
59.6 \\
84.9 \\
100.0\end{array}$} \\
\hline & $25-30$ & 313 & 43.3 & 43.3 & \\
\hline & $30-35$ & 183 & 25.3 & 25.3 & \\
\hline & Above 35 & 109 & 15.1 & 15.1 & \\
\hline & Total & 723 & 100.0 & 100.0 & \\
\hline \multirow[t]{6}{*}{ Education } & Master Full Research & 134 & 18.5 & 18.5 & \multirow{6}{*}{$\begin{array}{c}18.5 \\
34.7 \\
53.5 \\
99.3 \\
100.0\end{array}$} \\
\hline & Master Mixed Mode & 117 & 16.2 & 16.2 & \\
\hline & Master Taught Course & 136 & 18.8 & 18.8 & \\
\hline & $\mathrm{PhD}$ & 331 & 45.8 & 45.8 & \\
\hline & Post-Doctoral & 5 & .7 & .7 & \\
\hline & Total & 723 & 100.0 & 100.0 & \\
\hline \multirow[t]{9}{*}{ Field of research } & Pure and Applied Sciences & 116 & 16.0 & 16.0 & \multirow{9}{*}{$\begin{array}{c}16.0 \\
40.1 \\
51.9 \\
61.4 \\
83.5 \\
97.4 \\
99.3 \\
100.0\end{array}$} \\
\hline & Technology and Engineering & 174 & 24.1 & 24.1 & \\
\hline & Technology and communication & 85 & 11.8 & 11.8 & \\
\hline & Social Sciences & 69 & 9.5 & 9.5 & \\
\hline & Educational & 160 & 22.1 & 22.1 & \\
\hline & Human Resource and Development & 100 & 13.8 & 13.8 & \\
\hline & Clinical and health Sciences & 14 & 1.9 & 1.9 & \\
\hline & Other & 5 & .7 & .7 & \\
\hline & Total & 723 & 100.0 & 100.0 & \\
\hline
\end{tabular}

The relationship between performance of the researchers with collaborative learning and intention to use social media that measure through perceived ease of use, perceived usefulness; and found the reliability Cronbach's Alpha based on standardized items 0.890 . In analyzing the collected data, we followed the two-step procedure suggested by Hair et al. (2010). First, we examined the measurement model to measure reliability, convergent and discriminant validity. Then, we examined the structural model to investigate the strength and direction of the relationships between the theoretical constructs.

\subsection{Measurement model analysis}

Structural equation modelling (SEM) was employed as the main statical technique to analyse data with confirmatory factor analysis (CFA) using Amos 16. We assessed the overall goodness-of-fit using fit Indices ( $X^{2}, \mathrm{df}, \mathrm{X}^{2} / \mathrm{df}, \mathrm{RMR}, \mathrm{IFI}$, TLI, CFI and RMSEA). The initial confirmatory factor analysis showed an acceptable overall model fit. The measurement model results are shown in table1.

Table 2: Fit Indices for the Measurement Model

\begin{tabular}{ccccccccc}
\hline Model & $\mathrm{X}^{2}$ & $\mathrm{df}$ & $\mathrm{X}^{2} / \mathrm{df}$ & $\mathrm{RMR}$ & $\mathrm{IFI}$ & $\mathrm{TLI}$ & $\mathrm{CFI}$ & RMSEA \\
\hline Base & 2802.700 & 1289 & 2.174 & .035 & .932 & .925 & .932 & .043 \\
\hline
\end{tabular}

\subsection{Structural model analysis}

In the next step of the structural equation model (SEM), we run CFA to test structural framework. Tables 2 show the structural this framework also from table, it can be clearly seen that models' key statistics are very good. So, the framework is valid, and we can continue to analysis the results of the hypothesizes.

\subsubsection{Results of hypothesis testing}

The results of this research provide support for the framework and for the hypotheses regarding the directional linkage between the framework's variables. The parameter unstandardized coefficients and standard errors for the structural 
framework are shown in table three.

Table 3: Regression Weights

\begin{tabular}{|c|c|c|c|c|c|c|c|c|}
\hline H & Independent & Relationship & Dependent & Estimate & S.E. & C.R. & P & Result \\
\hline H1a & PU & $\longrightarrow$ & INUS & .255 & .034 & 7.534 & ${ }^{* * *}$ & Supported \\
\hline H2a & PEU & $\longrightarrow$ & INUS & .350 & .035 & 9.957 & ${ }^{* * *}$ & Supported \\
\hline H2b & PEU & $\longrightarrow$ & $\mathrm{CL}$ & .391 & .039 & 9.935 & ${ }^{* * *}$ & Supported \\
\hline H1b & $\mathrm{INUS}$ & $\longrightarrow$ & $\mathrm{CL}$ & .199 & .039 & 5.099 & ${ }^{* * *}$ & Supported \\
\hline H3a & $\mathrm{PU}$ & $\longrightarrow$ & $\mathrm{CL}$ & .230 & .037 & 6.246 & ${ }^{* * *}$ & Supported \\
\hline $\mathrm{H} 3 \mathrm{~b}$ & $\mathrm{CL}$ & $\longrightarrow$ & $\mathrm{RS}$ & .290 & .028 & 10.196 & ${ }^{* * *}$ & Supported \\
\hline $\mathrm{H} 4 \mathrm{a}$ & $\mathrm{INUS}$ & $\longrightarrow$ & $\mathrm{RS}$ & .416 & .032 & 12.915 & ${ }^{* * *}$ & Supported \\
\hline $\mathrm{H} 4 \mathrm{~b}$ & $\mathrm{CL}$ & $\longrightarrow$ & $\mathrm{PR}$ & .300 & .031 & 9.553 & ${ }^{* * *}$ & Supported \\
\hline $\mathrm{H} 3 \mathrm{C}$ & $\mathrm{INUS}$ & $\longrightarrow$ & $\mathrm{PR}$ & .227 & .037 & 6.156 & ${ }^{* * *}$ & Supported \\
\hline $\mathrm{H} 5$ & $\mathrm{RS}$ & $\longrightarrow$ & $\mathrm{PR}$ & .334 & .038 & 8.683 & ${ }^{* * *}$ & Supported \\
\hline
\end{tabular}

C.R.: critical ratio or t-Value, PEU: perceived ease of use, PU: perceived Usefulness, CL: collaborative learning, INUS: intention to use social media ,RS: researchers satisfaction and PR: performance of the researchers.

The table three above and figure two below indicate that intention to use social media positively and significantly with researchers satisfaction $(\beta=0.416, p<0.001)$ Thus, hypothesis $\mathrm{H} 4 \mathrm{a}$ was supported where there's a significant relationship between intention to use social media and researchers satisfaction to impact the performance of the researchers through perceived ease of use, perceived usefulness by using social media.

Findings in table 2 also the perceived ease of use positively and significantly with collaborative learning was ( $\beta=$ $0.391, p<0.001$ ); Hence, hypothesis H2b was supported where there's a significant relationship between perceived ease of use and collaborative learning. Hence, discussions with group member or supervisors improve performance of the researchers by using social media through collaborative learning.

Findings in table 2 also confirmed that perceived ease of use found positively and significantly with intention to use social media was $(\beta=0.315, p<0.001)$; Thus, hypothesis $\mathrm{H} 2 \mathrm{a}$ was verified supported where there's a significant relationship between perceived ease of use and intention to use social media that improve performance of the researchers when use social media also the ease to get knowledge and information sharing.

Next, hypothesis $\mathrm{H} 5$ confirmed that researchers satisfaction positively and significantly with performance of the researchers was $(\beta=0.334, p<0.001)$ Thus, hypothesis $\mathrm{H} 5$ has a direct positive and significant effect where there's a significant relationship between researchers satisfaction and performance of the researchers. Hence, allows the exchange of information with group members, and facilitates discussion with researchers.

Findings in table 2 also the collaborative learning positively and significantly with performance of the researchers was $(\beta=0.300, p<0.001)$; Hence, hypothesis $H 4 b$ was supported where there's a significant relationship between collaborative learning and performance of the researchers. Therefore, the performance of the researchers when collaborative learning with other researchers.

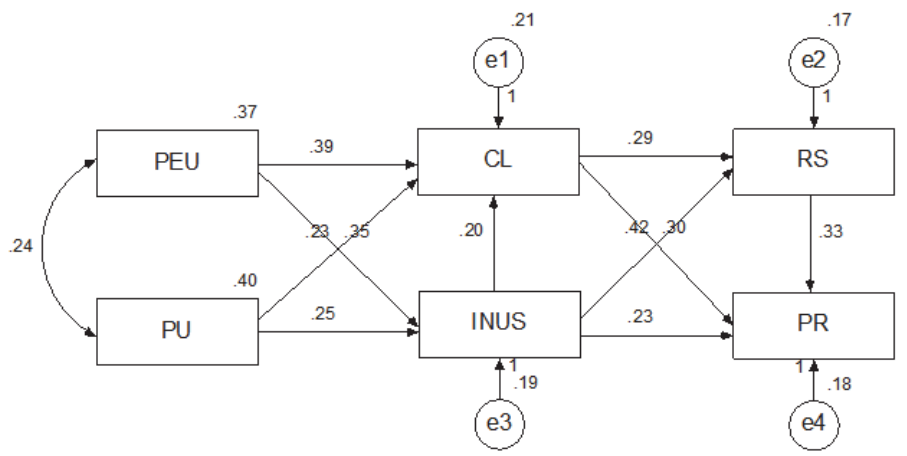

Figure 2: Results for the proposed framework 
Findings in table 2 also the collaborative learning positively and significantly with researchers satisfaction was $(\beta=0.290$, $p<0.001)$; Thus, hypothesis H3b was supported where there's a significant relationship between collaborative learning and researchers satisfaction. Thus, the researchers learn how to work with others effectively and usefulness.

The next, hypothesis $\mathrm{H} 1 \mathrm{a}$ confirmed that perceived usefulness positively and significantly with intention to use social media was $(\beta=0.255, p<0.001)$; Hence, hypothesis $\mathrm{H} 1 \mathrm{a}$ was supported where there's a significant relationship between perceived usefulness and intention to use social media. Thus, easy to get information and facilitates discussion with peers.

The next, hypothesis $\mathrm{H} 3 \mathrm{a}$ confirmed that perceived usefulness positively and significantly with collaborative learning was $(\beta=0.230, p<0.001)$; Thus, hypothesis $\mathrm{H} 3 \mathrm{a}$ was supported where there's a significant relationship between perceived usefulness and collaborative learning. Thus, actively exchanged the ideas with other research and able to develop the research skills through collaborative learning. Findings in table 2 also the intention to use social media positively and significantly with performance of the researchers was $(\beta=0.227, p<0.001)$; Thus, hypothesis H3c was supported where there's a significant relationship between intention to use social media and performance of the researchers. So, performance of the researchers improve when usefulness and ease to use of social media by researchers.

The final hypothesis $\mathrm{H} 1 \mathrm{~b}$ confirmed that intention to use social media positively and significantly with collaborative learning was $(\beta=0.199, p<0.001)$; Thus, hypothesis $\mathrm{H} 1 \mathrm{~b}$ was supported where there's a significant relationship between intention to use social media and collaborative learning. Therefore, researchers if intentions to use social media that will be improve collaborative learning and performance of the researchers.

Table 4 shows the Pearson correlation coefficient at $99 \%$ confidence level. The best correlation was found between the perceived ease of use with performance of the researchers with correlation coefficient of 0.815 . The characters on table 1 as follows: perceived ease of use (PEU), perceived usefulness(PU), intention to use social media (INUS), collaborative learning (CL), researchers' satisfaction (RS) and performance of the researchers (PR).

Table 4: Descriptive statistics and correlation matrix

\begin{tabular}{|c|c|c|c|c|c|c|}
\hline & PEU & PU & INUS & CL & RS & PR \\
\hline PEU & 1 & & & & & \\
\hline PU & $.842^{* *}$ & 1 & & & & \\
\hline INUS & $.769^{* *}$ & $.736^{* *}$ & 1 & & & \\
\hline CL & $.827^{* *}$ & $.769^{* *}$ & $.715^{* *}$ & 1 & & \\
\hline RS & $.752^{* *}$ & $.740^{* *}$ & $.794^{* *}$ & $.751^{* *}$ & 1 & \\
\hline PR & $.815^{* *}$ & $.746^{* *}$ & $.756^{* *}$ & $.794^{* *}$ & $.806^{* *}$ & 1 \\
\hline
\end{tabular}

**. Correlation is significant at the 0.01 level (2-tailed).

Result of Pearson correlation shows the dependent variable performance of the researchers has positive and significant correlation with perceived ease of use $(r=0.815, P<0.01)$ that positive and high correlation. correlation results of performance of the researchers with researchers satisfaction $(r=0.806, P<0.01)$.So the positive and significant correlation with researchers satisfaction; correlation results of performance of the researchers with collaborative learning $(r=0.794, P<0.01)$; the results of performance of the researchers with intention to use social media $(r=0.756, P<0.01)$, and the last correlation results of performance of the researchers with perceived usefulness $(r=0.746, P<0.01)$.

\subsection{Discussion}

These results highlight that performance of the researchers' relationship with perceived ease of use, perceived usefulness, intention to use social media and researchers satisfaction, is contributing to improve performance of the researchers through collaborative learning. In general, the using social media provides collaborative learning and useful for researchers, and using of social media in the research group would enable the researcher to accomplish tasks more quickly, due the ease of use and usefulness using the social media. Therefore, enhances effectiveness in the researches.

Also using social media will be easy to incorporate in the research group, using social media makes it easy to reach other researchers. Therefore, the perceived ease of use and researchers satisfaction about using social media for collaborative learning to improve their academic performance the result a high, Also the using social media for collaborative learning to improve performance of the researchers having a medium level through perceived usefulness. So, it needs to be encouraged to use the social media for research purposes but from the result above finding ease of 
use of social media because the using social media provides collaborative learning interaction and improve communication skills with supervisor, facilitates interaction with supervisor and allows the sharing information with other researchers. The collaborative learning with social media usage and acquired a high percentage when it comes to performance of the researchers at Universities. Since it helps make the researchers feel confident enough to presenting the social media by collaborative among researchers also researchers and supervisors that make ease to get resource, more information and knowledge. The collaborative learning experience in the social media environment is better than in a face-to-face learning, the researchers was able to develop research skills through members' collaboration and the researchers actively exchanged the ideas with research group members because the using of social media ease and useful. and the researchers intend to use social media for getting resources from my supervisor, researchers would not mind to switch over to another social media if it has better functionalities, also the researchers intend to use social media to improve the research skills and using of social media to build a researchers - supervisor relationship and this improves performance of research and using of social media and this will improve the research, by using of social media to facilitate academic activities and coordinate with other researchers.

\section{Conclusion and Future Work}

In this study suggested TAM predictors to improve collaborative learning by intention to use social media between researchers they are as follows with perceived ease of use and perceived usefulness. The findings showed that social media facilitates the collaborative learning and academic experience of the participants, although greater interaction is called for between students, their peers and their teachers this improve researchers satisfaction and performance of the researchers. The researcher recommends future work to examine additional factors that influence collaborative learning to enhance students' academic performance while taking demographic factors in consideration.

\section{Acknowledgements}

This material is based upon work supported by Instructional Development Grant (IDG) and Research University Grant (RUG) Universiti Teknologi Malaysia, and the Academy of Sciences for the Development World (TWAS) Research Grant under Vote No. 08216,02J 57, and 10-147 RG/ITC/AS_C; UNESCO FR:3240246311. Any opinions, findings, and conclusions or recommendations expressed in this material are those from the authors and do not necessarily reflect on the views of the Universiti Teknologi Malaysia and the Academy of Sciences for the Development World; also supported by Faculty of Marine, Hodeidah University, Hodeidah, Yemen.

\section{References}

Ajjan, $H_{\text {., }}$ and Hartshorne, R (2008) Investigating faculty decisions to adopt Web 2.0 technologies: theory and empirical tests. The Internet and Higher Education, 11(2), 71e80.

Akiyoshi, M (2008) Knowledge sharing over the network. Thin Solid Films, 517, 1512-1514.

Al-rahmi, W., and Othman, M (2014) The Improvement of Students' Academic Performance by Using Social Media through Collaborative Learning in Malaysian Higher Education.Asian Social Science; Published by Canadian Center of Science and Education, Vol. 10, No. 8; 2014.

Al-rahmi, W., and Othman, M (2013) Using TAM Model To Measure The Use Of Social Media For Collaborative Learning.International Journal of Engineering Trends and Technology (IJETT) - Volume 5 number 2 - Nov 2013.

Al-rahmi, W., and Othman, M (2013a) Evaluating student's satisfaction of using social media through collaborative learning in higher education. International Journal of advances in engineering \& technology.

Al-rahmi, W. M. Othman, M.S. Yusof, L.M and Musa. M.A. (2015a). Using Social Media as a Tool for Improving Academic Performance through Collaborative Learning in Malaysian Higher Education. Review of European Studies, 7(3), p265.

Al-rahmi, W. M., Othman, M. S., and Yusuf, L. M. (2015b). Social Media for Collaborative Learning and Engagement: Adoption Framework in Higher Education Institutions in Malaysia. Mediterranean Journal of Social Sciences,6(3 S1), 246.

Anderson, P (2007) What is Web 2.0? Ideas, technologies and implications for education. UK: JISC Technology \& Standards Watch. Retrieved from www.jisc.ac.uk/media/documents/techwatch/tsw0701b.

Arnold, N., and Paulus, T (2010) Using a social networking site for experiential learning: Appropriating, lurking, modeling and community building. Internet and Higher Education, 13, 188-196.

Arrington, M (2009) YouTube EDU launch, So Go to Learning Something.

Banks (2006) Reflections on the use of ARS with small groups. In D. A. Banks (Ed.), Audience response systems in higher education (pp. 373-386). Hershey, PA: Information Science Publishing.

Boulos, M., Maramba, I., and Wheeler, S (2006) Wikis, blogs and podcasts: A new generation of webbased 
tools for virtual collaborative clinical practice and education., Journal of the American Dietetic Association, 107(4), 553-555.

Burnett, C. and Merchant, G (2011) Is there a space for critical literacy in the context of social media? English Teaching: Practice and Critique, 10 (1): 41-57.

Chandra, V. and Watters, J (2012) Re-thinking physics teaching with web-based learning. Computers \& Education, 58, 631-640.

Chen, B., and Bryer, T (2012) Investigating instructional strategies for using social media in formal and informal learning. International Review of Research in Open and Distance Learning, 13(1), 87-104.

Davis, F.D., Bagozzi, R.P. and Warshaw, R.P (1989) User acceptance of computer technology: a comparison of two theoretical models. , Journal of Management Science, Vol. 35 No. 8, pp. 982-1003.

DeGennaro, D (2008) Learning designs: An analysis of youth-initiated technology use. Journal of Research on Technology in Education, 4 (1): $1-20$.

Ebner, M., Lienhardt, C., Rohs, M., and Meyer, I (2010) Microblogs in higher education: A chance to facilitate informal and processoriented learning? Computers \& Education, 55, 92-100.

Ewbank, A., Foulger, T., and Carter, L (2010) Red Bull, Starbucks, and the changing face of teacher education. Phi Delta Kappan, 92(2), 25-28. Retrieved from EBSCOhost.

Gallini, S. and Moely, B (2003) Service-learning and engagement, academic challenge and retention. Michigan Journal of Community Service Learning5-14

Gomez, M., Schieble, M., Curwood, J. and Hassett, D (2010) Technology, learning and instruction: Distributed cognition in the secondary English classroom. Literacy, 44 (1): 20-27.

Greenhow, C., Robelia, B. and Hughes, J (2009) Learning, teaching, and scholarship in a digital age.Educational Researcher, 38: 246259.

Hastie, P., Casey, A. and Tarter, A-M (2010) A case study of wikis and student-designed games in physical education.Technology, Pedagogy and Education, 19 (1): 79-91.

Hair, J.F., W.C. Black, B.J. Basin, and Anderson R.E (2010) Multivariate data Analysis. (7 thedition.). New

Jersey: Upper Saddle River, Pearson Prentice Hall.

Heafner, T and Friedman, A (2008) Wikis and constructivism in secondary social studies: Fostering a deeper understanding. Computers in the Schools, 25, 288-302.

Hrastinski, S (2009) A theory of online learning as online participation. Computers \& Education, 52, 78-82.

Huang, Y., Jeng, Y., and Huang, T (2009) An Educational Mobile Blogging System for Supporting Collaborative Learning. Educational Technology \& Society, 12 (2), 163-175.

Junco, R., Heiberger, G. and Loken, E (2011) 'The effect of Twitter on college student engagement and grades', Journal of Computer Assisted Learning, Vol. 27, No. 2, pp.119-132.

Junco, R (2012b) Too much face and not enough books: The relationship between multiple indices of Facebook use and academic performance. Computers in Human Behavior, 28, 187-198.

Kabilan, M., Ahmad, N., and Abidin, M (2010) Facebook: An online environment for learning of English in institutions of higher education? Internet and Higher Education, 13, 179-187.

Kim, H., Chan, H., and Gupta, S (2007) Value-based adoption of mobile internet: An empirical investigation. Decision Support Systems, $43,111-126$.

Kim, G., Park, S., and Oh, J (2008) An examination of factors influencing consumer adoption of short message service (SMS).Psychology \& Marketing, 25, 769-786.

Kwon, O., and Wen, Y (2010) An empirical study of the factors affecting social network service use.Computers in Human Behavior, 26, $254-263$.

Liu, C., Liu, K., Chen, W., Lin, C. and Chen, G (2011) Collaborative storytelling experiences in social media: Influence of peer-assistance mechanisms. Computers \& Education, 57 (2): 1544-1556.

Livingstone, S. and Brake, D (2010) On the rapid rise of social networking sites: New findings and policy implications. Children and Society, 24: 75-83.

Maher, D (2010) Supporting students' transition from primary school to high school using the Internet as a communication tool. Technology, Pedagogy and Education, 19 (1): 17-30.

Maher, D (2009) The importance of elementary school students' social chat online: Reconceptualising the curriculum. Computers \& Education, 53: 511-516.

Minocha, S (2009) Role of social software tools in education: A literature review. Education \& Training, 51 (5-6): 353-369.

Moon.J and Kim Y (2001) "Extending the TAM for a world-wide-web context", Information Management 38 (2001) 217-230.

Mazman, S., and Usluel, Y (2010) Modeling educational use of Facebook. Computers \& Education, 55(2), 444-453.

Pelling E , White K . (2009) .The theory of planned behavior applied to young people use of social networking web sites, CyberPsychology \& Behavior 2009; 12:755-9.

Pifarre, M. and Fisher, R (2011) Breaking up the writing process: how wikis can support understanding the composition and revision strategies of young writers. Language and Education, 25 (5): 451-466.

Owen, M., Grant, L., Sayers, S. and Facer, K (2006) Social software and learning. Bristol: Futurelab.

Sánchez, Cortijo and Javed (2014)Students' perceptions of Facebook for academic purposes . Computers \& Education journal homepage: www.elsevier.com/locate/compedu.

Selim, H (2003) An Empirical Investigation of Student Acceptance of Course Websites. Computers and Education, 40(4), 343-60. 
Shahrinaz Ismail (2010) An evaluation of students' identity-sharing behavior in social network communities as preparation for knowledge sharing. International Journal for the Advancement of Science \& Arts, 1(1), 14-2.

Smith, S., and Caruso, J (2010) The ECAR study of undergraduate students and information technology.

EDUCAUSE Center for Applied Research ECAR. Retrieved from http://www.educause.edu/ecar.

So, H., and Brush, T (2008) "Students perceptions of collaborative learning, social presence and satisfaction in a blended learning environment: relationships and critical factors", Computers \& Education, 51(1), 318-336.

Syahrir, and Fatin (2009) Kesan aplikasi social maya. (2009, December 23). Kosmo.

Venkatesh, V. and Bala, H (2008) Technology Acceptance Model 3 and a research agenda on interventions.Journal of Decision Sciences, Vol. 39 No. 2, pp. 273-315.

Venkatesh, V., Morris, M., Davis, G., and Davis, F (2003) User acceptance of information technology: Toward a unified view. MIS Quarterly, 27(3), 425-478.

Yampinij, S., Sangsuwan, M., and Chuathong, S (2012) A conceptual framework for social network to support collaborative learning ( $\mathrm{SSCL}$ ) for enhancing knowledge construction of grade 3 students, 46,

Yang, S., and Chen, I (2008) A Social Network-based System for Supporting Interactive Collaboration in Knowledge Sharing over Peerto-Peer Network. International Journal of Human-Computer Studies, 66 (1), 36-50.

Yu, A., Tian, S., Vogel, D., and Kwok, R. C (2010) Can learning be virtually boosted?: An investigation of online social networking impacts. Computers \& Education, 55, 1494-1503.

Zhang, J., Scardamalia, M., Lamon, M., Messina, R. and Reeve, R (2007) Socio-cognitive dynamics of knowledge building in the work of 9- and 10-year-olds. Education Technology Research and Development, 55: 117-145.

Zywica, J., Richards, K. and Gomez, K (2011) Affordances of a scaffolded-social learning network, On the Horizon, 19 (1): $33-42$. 